\title{
Web-Based Virtual Transcript Processing and Transfer For Nigerian Universities
}

\author{
*B.C.E Mbam (Ph.D.) And ** G.N. Odachi (M.Sc.) \\ Department of computer Science Michael Okpara University of Agriculture, Umudike, Abia State, Nigeria \\ Department of Computer Science, Nwafor Orizu College of Education Nsugbe, Anambra State, Nigeria
}

\begin{abstract}
Transcript cum result processing and transfer has become a very big administrative problem in our universities in Nigeria. In view of the above, web based virtual transcript processing and transfer system was developed. The model adopted for the design was structured systems Analysis and Design Methodology (SSADM). Visual Basic.Net, Ado.net, HTML and Java script were used in developing the system. The developed new system has quickened the processing and transfer of transcripts and by extension internal results.
\end{abstract}

Keywords: Virtual, administrative, processing, structured, methodology

\section{Introduction}

Over the years, one has witnessed a phenomenal expansion of the Nigerian university system which started with oil boom of the 1970's doubling every four years. As of today, Nigeria has more than one hundred universities (Wikipedia 2011). There has been also astronomical increase in population of Nigeria from 57 million in 1970 to 162.5 million in 2012. Therefore, the observed phenomenal increase in the number of universities in the country is a direct consequence of increase in population and the resultant increased demand for education.

The increase in the number of students in Nigerian universities has posed great challenges for university administration. These challenges include, delay in computation and issuance of results, certificates, transcripts and absence of real time services/information dissemination etc.

Commenting on the challenges facing Nigerian Universities, Ogu (2008) observed that Nigerian University education needs reformation for it to meet the societal needs. Nigerian universities must seek to remove the constraints that prevent them from responding to the needs of rapidly changing society. This can only be achieved by introducing democratic university structures and management style.

Writing on transcript request from Nigerian universities, Abidde (2008) noted that:

If you have ever attempted to secure academic transcripts from any Nigerian University, or from other institutions of higher learning, you will know how difficult and frustrating it can be. And in fact such difficult experiences are not limited to schools. Procuring medical records or government documents can also be an uphill task. Although securing documents and transcripts may be easier if you live in Nigeria, attempting to do so from abroad can be annoying, traumatic and time consuming. I am inclined to believe that it is easier to rob a bank than to secure transcripts and other official documents.

Abidde also stressed that apart from the official fee to be paid to the school, facilitators within the university system would need their palms to be greased. Moreover, friends and relatives who spent their time going back and forth must be compensated. Therefore, transcript that ordinarily should cost no more than $\$ 50$ may end up costing up to $\$ 200$.

Adekiigbe and Amosa (2009) observed administrative problems in the issuance of transcripts in our tertiary institutions of high learning. According to them, one of the top challenges for institutions and students of higher learning in Nigeria today is the issuance and collection of transcripts. Students sometimes apply for transcripts from their respective institutions and it takes several months before such transcripts could be issued to the applicants. These scenarios do cost the applicant a number of failures. Admission process is not complete without including the transcripts with the admission forms especially for students going for higher degrees in other institutions. So, in some cases students lose admission due to late arrival of transcripts. In view of the above, the authors cited above conceptualized the requirements analysis process for development of an Agent-Based Online Transcript application and subsequent issuance of the transcript.

There is the need to change the current scenario for the better through information technology. There is no gain saying the fact that information technology (IT) has revolutionized the way we live, think and do 
business.

It has changed and is still changing the way we do things in our houses, offices, schools and other places and had changed how ideas are communicated in the society today. This can be applied to transcript processing and transfer in Nigerian universities.

Tabe (2007) observed that the quickest route out of economic stagnation is information technology skills acquisition. He noted that Japan, South Korea and currently China represent the clearest modern example of countries, once regarded as backward and undeveloped, which have changed their fortunes by investing in IT. Tabe's comment points to the fact that information technology could be successfully applied to transcript processing.

Odachi (2009) contended that the world is being swept by "infomania", the belief that the person who possesses the most information has advantage over others who have little or no access to it. We are in a new world of globalization, where modern life is dominated by technology and currently what happens in any part of the world is instantly transmitted to other parts through information technology.

Speaking on the importance of technology as a change agent, Emeagwali (2009) contended that intellectual capital and technology now rule the world and that natural resources such as gold, diamond, oil etc are no longer the primary determinant of wealth. In view of the above almost all businesses and organizations, especially in advanced countries, have become aware that they must adapt to the changing technology or be left behind - hence the adoption of IT in their service delivery.

Presently, there are great potentials of IT's as tools for enhancing people's daily lives. It can act as a facilitator for government development programmes such as cassava and rice initiative programmes that have been introduced to combat the food problems that are currently facing the citizens of Nigeria (Akinyede, Boyinbode and Alese, 2009).

Mirilla (2009) observed that Nigeria is still operating a twenty century economy in the age of knowledge economy. Advances in technology, he said, have a "flat world". The Internet and broadband communications have reduced distances to nothing, which in turn has created a redefinition of national borders. Global out sourcing, driven primarily by information technology, is the new economy and nations that are quick to identify and exploit these opportunities realigned their production of human capital to take advantage of the new economy.

Obot (2009) contended that information technology can help solve administrative problems. He stressed that the developing nations of the world are politically backward because their strive to govern themselves has been punctured by electoral malpractice, corruption and lack of transparency which could be addressed by IT. It could be inferred from the authorities cited above that IT can also be applied successfully to transcript processing.

It is the belief of the researchers that information technology could be used to change universities administrative system in terms of result, transcript processing and issuance for the better.

\section{Materials And Methods.}

Data was collected from primary and secondary sources and analyzed to investigate the working of the current system. Structured Systems Analysis Design and Methodology SSADM was applied to describe the existing system. Stair (1986) defined systems analysis as the study of an existing system, the purpose of which is to determine if there are any problems or shortcomings of the system. From the data collected and analyzed, it has been established that:

- Web portals used by most of the universities were not designed to cope with the large volume of data generated by the current staff and student population, especially students' results.

- Most web portals do not take care of transcript processing and transfer and, therefore, manual method is still used.

- Information updating is not flexible as they are rarely done on daily basis.

- The current System lacks real time services

- In some cases, the current system is affected by situational/human factors such as emotion, tiredness, worries etc

The above points constituted the weaknesses of the current system. For instance in the current system, for you to get information or data on any matter in some of the universities, you have to travel to the university. If you fail to meet the person in charge of the section you are trying to obtain data or information from, you have to wait or come the next day. It is not even guaranteed that you are going to get what you requested for the next day. It might take some days or one to two weeks or more. This applies to transcript processing and hence the delay.

\section{Design of the New System.}

In the new system design, the product (Transcript/result processing) was broken down into components 
called modules. The modules consist of student registration, curriculum set up, exam score entry and view results/transcript. Each of the 4 modules has its own sub modules. For instance student registration module has its sub module made up of Name, Reg number, Faculty, Department, level and save.

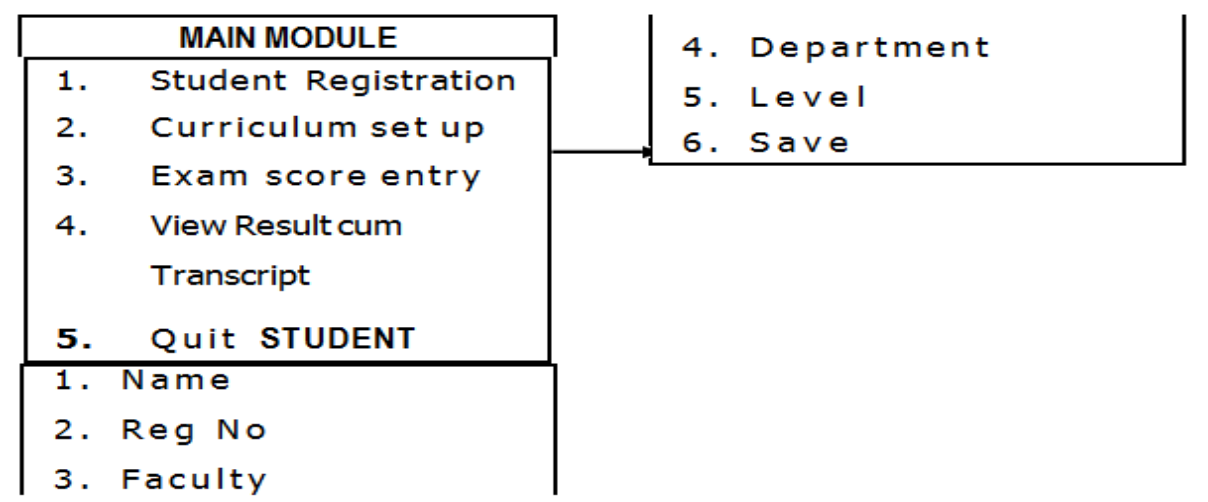

Fig 1:The main module and the student registration sub-module

Result/Transcript processing starts with the registration of the students and their data stored or saved in the database. This is followed by making entry of courses and setting up the curriculum and storing it in the database. When the students take exams, their scores are entered and equally stored.

When one, therefore, clicks or selects view result or transcript, they appear on the screen. As long as the data for the students are in the database, the system automatically calculates the results and transcripts. The transcript can be printed, signed and forwarded by e-mail to the institution where it is required and acknowledgement of receipt of request and notice of transfer of transcript sent the applicant.

Note that: The transcript will only be shown to the staff in charge of it and not to the applicant. So, transcript processing and issuance is the exclusive preserve of the staff assigned to do it and not the students. The students can only view their internal result but not transcript.

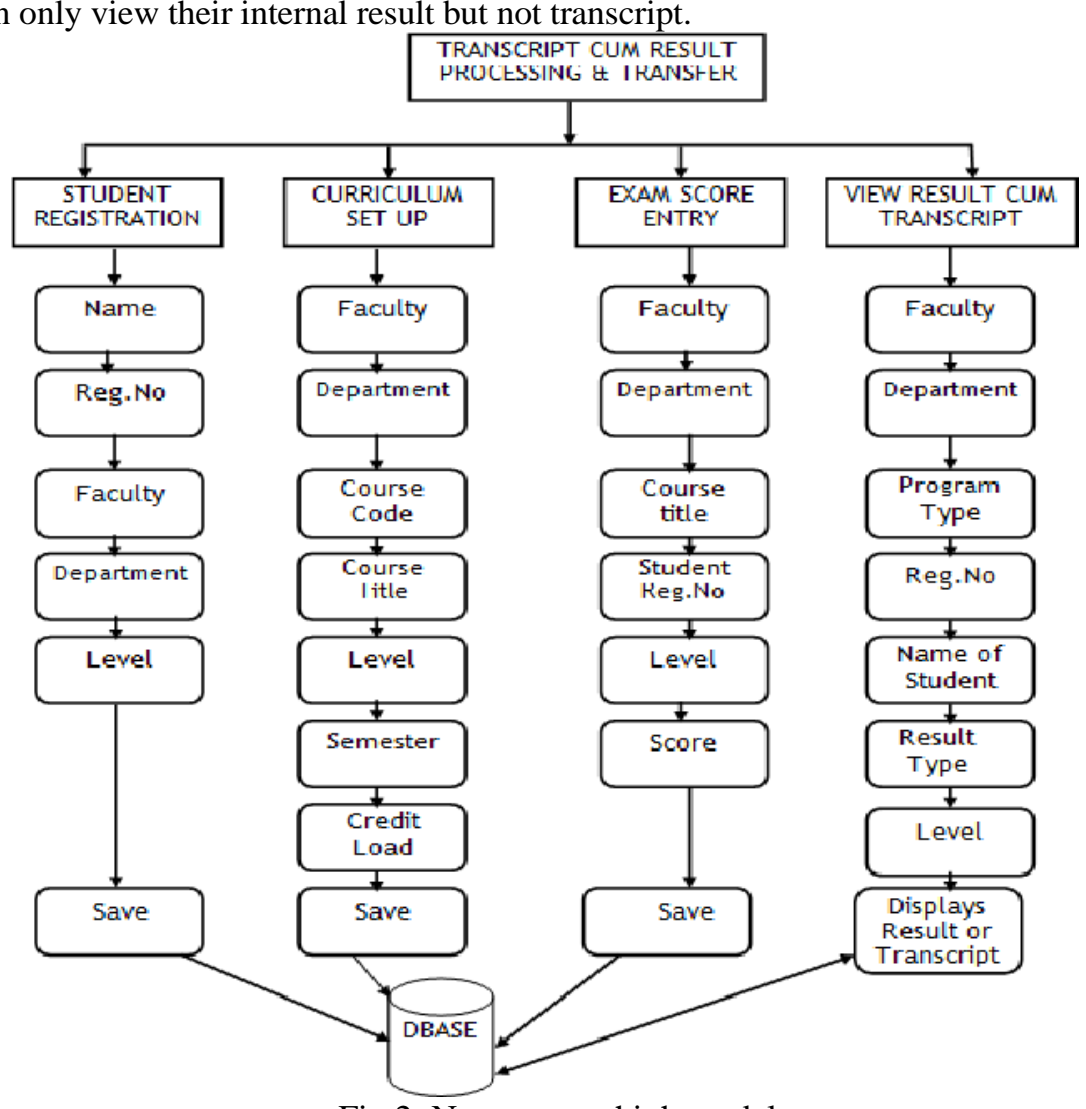

Fig 2: New system high model 


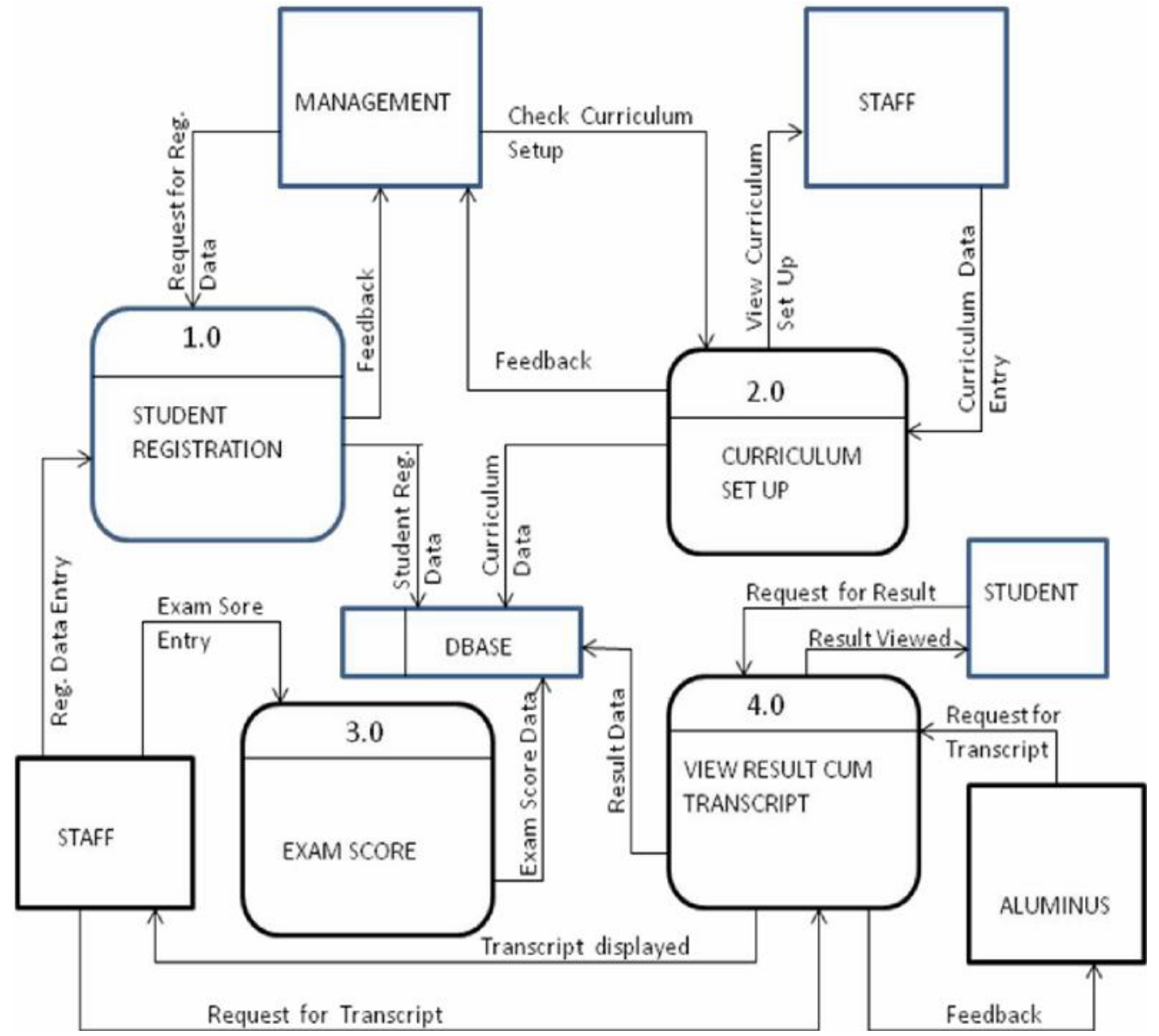

\section{Database Architecture}

Fig 3: Data flow diagram of the new system.

The Database management system used for this design is Microsoft SQL server 2008. IT is a powerful relational data base management system (RDBMS) (see fig 4).

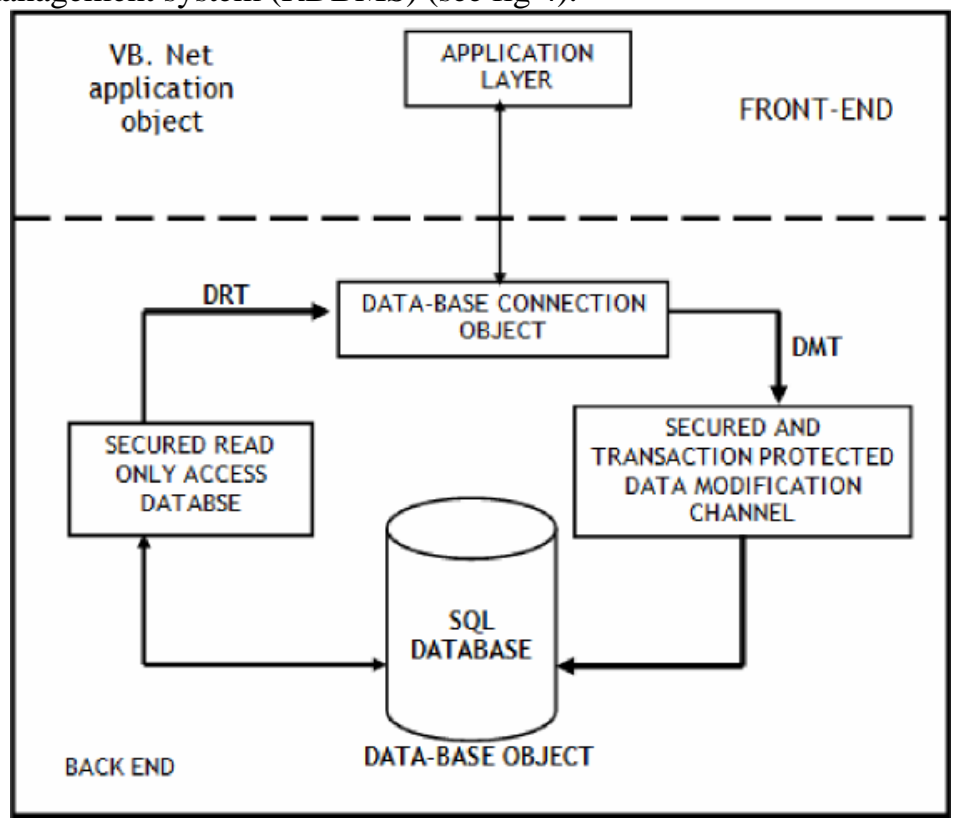

Fig 4: Database Architecture

In the diagram above dotted line is used to demarcate application object (Front end) and database object (BackEnd). Data base access 
object known as ADO.Net, has three objects vital to our database operation. They are:

- Connection object

- Command object

- Data reader object

The functions of these objects are as follows:

Connection Object connects application objects layer and database object. For instance, for transaction to take place, you call the open method in the connection object to open the channel between front end (application object layer) and Back-end (database object). Thus, access to the database is created.

Command Object is used to execute instructions in the database. There are two main types of transactions in the database - Data Modification Transaction (DMT) and Data Read Transaction (DRT). DMT consists of the following transactions:

Insert-to insert new records.

Update - to modify existing records.

Delete- to delete existing records

DTR Reads data from database.

Data Reader Objects is used to read data from database. Its function is read only operation. There is no modification transaction.

\section{System Development Tools}

Software development tools for implementation of the system include:

- $\quad$ The operating system: Windows XP and above

- $\quad$ Programming language: Visual Basic.Net 2008

- Web development tools: ASP.Net, Ado.Net and Java script.

- Database: SQL server 2008 (DBMS)

- Anti Virus software: Avers,2038

\section{Result and Discussion}

With the new system developed, admitted students are registered right from on set. The exam scores are entered as soon as the scores are ready. The system, thus generates results and transcripts as soon as the request is made. This is stored in the database and can be retrieved instantly on demand. The transcript is sent via e-mail to the required institution and the student duly informed of the transaction done.

The new system developed can do the following:

- Monitor and report any transaction done in the system

- Remove calculation error inherent in the manual system.

- $\quad$ Reduce the time wasted and cost of traveling inherent in the old system

- Remove emotional and situational factors experienced in the current system.

- Offer real-time services in terms of result, transcript processing and transfer.

- Solve the problem of lost of records arising from lost of file since every student data are stored in the database.

The above mentioned benefits of the new system took care of the weakness of the current system. The problems inherent in the current system have certain implications. The students who want to do their post graduate studies are delayed. Others lost admission and scholarship due to non-submission of their transcripts as required.

\section{Conclusion}

The fact that the current method of result cum transcript processing is saddled with many problems is not in doubt. The system developed would definitely remove the problems of current system.

The new system when fully applied to university administration would be a big relief to students who want to further their studies without delay. The new system designed and developed is recommended to all the tertiary institutions in Nigeria and beyond.

\section{References}

[1]. Abidde, S.O. (2007). Requesting Transcripts from Nigerian Universities (online:www.nigeriavillagesquare.com/articlesIsabella-oabidde..) Accessed 10/5/2012

[2]. Adekiigbe, A. and Amosa B.M.G (2009). Journal of Computer Science and its Application, Vol. 16, No 2 Pp.45.

[3]. Akinyede, R.O., Boyinbode O.K., and Alese B.K. (2009). Poverty reduction in Nigeria, using information technology, NCS international Conference Vol. 20 Pp.3

[4]. Emeagwali, P. (2009). Around the Globe, Technology Widens Rich-poor Gap: A paper presented at African diaspora conference in Tucson, Arizona http://www.phi lip emeagwali.com. Accessed 5/1/2009.

[5]. Mirilla, D.F (2009). Information Technology as a Strategy to Developing Nigeria's New Economy, NCS $9^{\text {th }}$ International Conference, Conference proceedings, Vol. 20. 
[6]. Obot, O.U. (2009). Enhancing the Socio-Economic development of developing countries through Information and communication technology (ICT), NCS international conference, conference proceeding, Vol 20.

[7]. Odachi, G.N. (2009) "Introduction to Information and Communication Technology", Computer Application and Operations, Edited by Nwajiobi and Osegbo, West and Solomon publishers, Onitsha, page 64-72.

[8]. Ogu,O.P.(2008) Challenges Facing Nigerian Universities. Nigeria World (Baltimore),30 (online:http://nigeriaworld.com/ articles/2008/Sep/300.html).

[9]. Stair, R.M. (1986). Computer in Today's World, New York, Irwin publishers.

[10]. Tabe, J.A. (2007) pathway to a Rewarding IT career, in ICT Today magazine Vol. 1 No. 2.

[11]. Wikipedia (2011) List of Universities in Nigeria (http://en.Wikipedi. org. /wikipedia/list of universities-in-Nigeria. accessed 15/16/2013. 